\title{
Evaluation of Gastroesophageal Reflux Disease Using the Bravo Capsule pH System
}

\author{
Rona Marie A Lawenko' and Yeong Yeh Lee ${ }^{2 *}$ \\ ${ }^{1}$ Section of Gastroenterology, De La Salle Health Sciences Institute, Dasma-rinas City, Cavite, Philippines; and ${ }^{2}$ School of Medical Sciences, \\ Universiti Sains Malaysia, Kubang Kerian, Kota Bahru, Kelantan, Malaysia
}

\begin{abstract}
Gastroesophageal reflux disease (GERD) is a disease predominantly seen in the West but there is a rising trend in Asia. Ambulatory 24-hour catheter-based pH monitoring has been the de facto gold standard test for GERD that correlates symptoms with acid reflux episodes. However, drawbacks such as patients' discomfort, and catheter displacement render the test as cumbersome and errorprone. The Bravo pH wireless system is designed to be user-friendly and has an added advantage of prolonged pH monitoring. The system is comparable to the catheter-based pH monitoring system in terms of diagnostic yield and symptom-reflux association. Indications include evaluation of patients with refractory GERD symptoms and prior to anti-reflux surgery. Bravo utilizes a wireless pH-sensing capsule with a complete prepackaged system, and a data processing software. The capsule may be positioned indirectly using endoscopic or manometric landmarks or under direct endoscopic guidance. Optimal threshold cut-off values are yet to be standardized but based on available studies, for the Asian population, it may be recommended for total \% time pH $<4$ of 5.8 over 48 hours. Cost is a limitation but capsule placement is relatively safe although technical failures may be seen in small percentage of cases.
\end{abstract}

(J Neurogastroenterol Motil 2016;22:25-30)

Key Words

Asia; Esophageal pH monitoring; Gastroesophageal reflux disease

\section{Introduction}

Gastroesophageal reflux disease (GERD) is on the increase in Asia with prevalence ranging from $5 \%$ up to $18 \% .{ }^{1}$ Heartburn and regurgitation are typical symptoms of GERD, but are unreliable in terms of distinguishing GERD from functional gastrointestinal (GI) diseases particularly among Asians. ${ }^{2,3}$ In addition, the presence of reflux symptoms lack direct correlations with increased esophageal acid exposure, as well as endoscopically proven esophagitis. ${ }^{2,3}$

In a symptomatic Asian patient with normal endoscopic find- ings, the diagnosis of GERD would often rely on documented high esophageal acid exposure. Ambulatory 24-hour $\mathrm{pH}$ monitoring, first introduced in 1974, was developed to detect abnormal levels of acid reflux in the lower esophagus. ${ }^{4,5}$ Conventional $\mathrm{pH}$ monitoring requires a nasopharyngeal catheter with $\mathrm{pH}$ electrode placed $5 \mathrm{~cm}$ above the lower esophageal sphincter to document distal esophageal acid exposure and correlate this with reflux symptoms. ${ }^{5}$ Although highly sensitive and specific, several pitfalls with this procedure have been cited. Drawbacks include patient discomfort due to nasal and pharyngeal irritation from the $\mathrm{pH}$ catheter. Oftentimes, patients limit their daily physical activities and alter their diets, which may

Received: September 25, 2015 Revised: December 7, 2015 Accepted: December 7, 2015

(5) This is an Open Access article distributed under the terms of the Creative Commons Attribution Non-Commercial License (http://creativecommons. org/licenses/by-nc/4.0) which permits unrestricted non-commercial use, distribution, and reproduction in any medium, provided the original work is properly cited.

${ }^{*}$ Correspondence: Yeong Yeh Lee, MD, PhD, FACP, FRCP, FACG

School of Medical Sciences, Universiti Sains Malaysia, 16150 Kubang Kerian, Kelantan, Malaysia

Tel: +609-7676571, Fax: +609-7673949, E-mail: justnleeyy@gmail.com 
underestimate the amount of actual reflux episodes. Methodological difficulties such as incorrect placement and catheter migration have been observed which may affect test accuracy thus leading to erroneous results. ${ }^{3,4,6}$

A wireless pH capsule was designed and developed in 2003 to overcome these limitations. ${ }^{7,8}$ The Bravo $\mathrm{pH}$ wireless capsule system (Given Imaging; Medtronic Inc, Shoreview, MN, USA) is a device that is temporarily implanted in the distal esophageal mucosa to avoid the inconvenience of wearing a nasopharyngeal electrode. 5 The diagnostic yield of Bravo system was comparable to the catheter-based system as seen in studies performed in both the Caucasians and Asian populations. ${ }^{4,5}$ Symptom association with reflux episodes is likewise similar between the wireless and conventional $\mathrm{pH}$ monitoring systems. ${ }^{9}$ More importantly, the Bravo capsule was observed to be significantly better than the conventional system in terms of tolerability with minor impact on diet and daily activities. $^{10,11}$

\section{Test Equipment}

The Bravo $\mathrm{pH}$ monitoring system utilizes a wireless $\mathrm{pH}$-sensing capsule. The prepackaged system is composed of the following (Fig. 1): pH receiver kit; capsule with delivery system, an internal battery and transmitter; vacuum pump; suction tubes; calibration stand, buffer solution; infrared receiver device; and software. ${ }^{4,12}$ The capsule is oblong-shaped, measures $6 \mathrm{~mm} \times 5.5 \mathrm{~mm} \times 25 \mathrm{~mm}$ and has an antimony $\mathrm{pH}$ and reference electrode at its distal end. ${ }^{7,12}$ The delivery system consists of an 80-cm long, 6-Fr diameter tubular device with measurement markings to identify catheter distance from the incisors. ${ }^{13}$

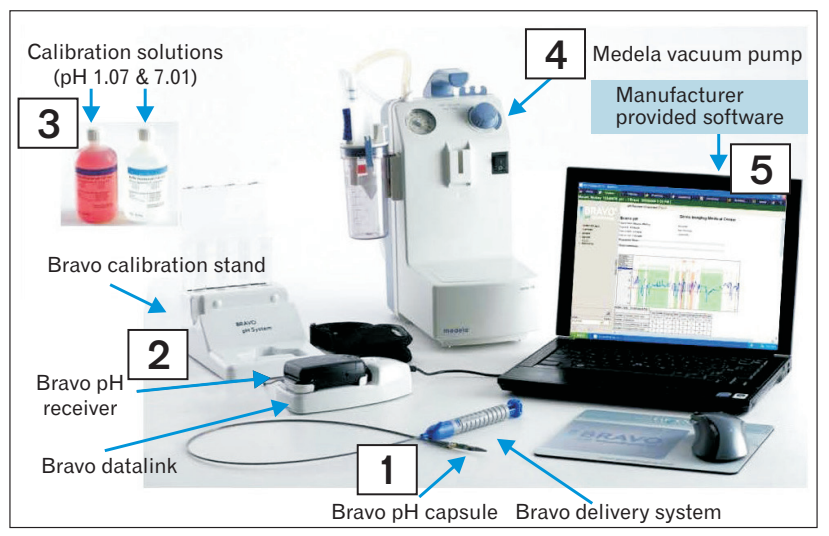

Figure 1. Components of the Bravo capsule system. Prepackaged system consists of (1) Bravo $\mathrm{pH}$ capsule with delivery system, (2) $\mathrm{pH}$ receiver kit, (3) buffer solution, (4) vacuum pump with suction tubes; and (5) manufacturer-provided software.
Prior to usage, the Bravo $\mathrm{pH}$ capsule is activated by a magnetic switch and requires $\mathrm{pH}$ calibration. The capsule is submerged in a buffer solution of $\mathrm{pH} 7.01$ for at least 10 minutes, at room temperature, calibrated, rinsed, and then recalibrated in the second buffer solution of $\mathrm{pH} 1.07$. The receiver hardware is also checked to confirm proper data transmission. ${ }^{14}$ The carrier frequency of the $\mathrm{pH}$ signal is in the $433-\mathrm{MHz}$ band. ${ }^{12}$ Digital data transmission occurs every 12 seconds with $2 \mathrm{pH}$ data-points obtained every 6 seconds. ${ }^{12,15}$ The average battery-life of a Bravo capsule may be up to 14 days. $^{16}$

\section{Test Procedure}

Prior to the test, medications such as proton pump inhibitors (PPIs) and H2-blockers should be discontinued for 14 days and at least 3 days respectively. ${ }^{5,10}$ Antacids should be stopped 24 hours before the study. ${ }^{17}$ Patients are instructed to fast for 6 hours prior to the procedure. Upper endoscopy is usually performed to guide placement of the capsule either through conventional or direct guidance.

After activation and calibration, connect the vacuum tubing to the Bravo delivery device and perform vacuum pump check to verify gauge reaches $700 \mathrm{mmHg}$. The Bravo capsule can be inserted through the nostril or mouth while the patient is in a left lateral decubitus position. Oral insertion is preferred compared to transnasal insertion due to difficulty in passing the delivery system through the angles of the nasopharynx. ${ }^{15}$ With conventional endoscopic guidance, the gastroesophageal junction (GEJ) is identified, followed by removal of endoscope and then the capsule is placed $6 \mathrm{~cm}$ proximal to the GEJ. ${ }^{12,14}$ This position is derived from observation that the high pressure zone of lower esophageal sphincter (LES) is typically 1 to $1.5 \mathrm{~cm}$ proximal to the GEJ. With direct endoscopic guidance, the endoscope is left in place within the esophagus while the Bravo delivery system is being deployed and capsule placed under direct view of the endoscope. ${ }^{18}$ Direct-guidance has been shown to be equally effective as conventional-guidance with the added advantage of avoiding a second endoscopy to confirm the placement.

More recently, manometry-guided placement has been shown to be equally suitable. ${ }^{19}$ With manometry guidance, the Bravo capsule is positioned at $5 \mathrm{~cm}$ above the proximal border of the LES if delivered transnasally. ${ }^{4,9,10}$ Alternatively, the Bravo capsule is better delivered orally because of tolerability, and by using a correction factor of $4 \mathrm{~cm}$ for the difference between oral and nasal intubation. A retrospective study suggests that manometry placement may be better since endoscopic placement resulted in higher acid exposure on day one and the cost might be higher. ${ }^{19}$ Furthermore, capsule 
misplacement with endoscopy is common especially more proximal displacement, however, misplacement is not necessarily associated with poor $\mathrm{pH}$ results. ${ }^{20}$

Once it is in the correct position, the vacuum pump is used to apply suction to the wall of the capsule. A vacuum pressure of more than $510 \mathrm{mmHg}$ for 15 to 30 seconds is required for successful deployment, although $700 \mathrm{mmHg}$ is usually recommended by the manufacturer. ${ }^{8,9,11,12}$ The activation button is pressed to deploy a spring-loaded, stainless-steel pin to attach the capsule to the mucosa. The activation button is then turned clockwise at $90^{\circ}$ to release the capsule from the delivery system. ${ }^{12}$ Lastly, the data receiver is then attached to a belt around the patient's waist. ${ }^{7,9}$ During bath or sleep, the receiver should be within 3 to 5 feet of the patient for successful transmission. ${ }^{12,15}$ Figure 2 illustrates the steps in capsule placement.

Patients are instructed to keep a daily diary to log their symptoms, meals, and sleep. Acidic drinks such as coffee, soda, cranberry, and orange juice should be avoided. ${ }^{15}$ Subjects are encouraged to perform their regular daily physical activities during the test. ${ }^{14}$ Data recording and storage of $\mathrm{pH}$ data typically occur over 48 hours.

\section{Analysis of Bravo pH Data}

The data obtained from the capsule are recorded and processed by the manufacturer provided software. ${ }^{9}$ Patients' diary entries and other temporal data are entered manually using the software. ${ }^{12}$ The parameters measured are: percent of total time of $\mathrm{pH}<4$; the total number of reflux episodes in both the upright and supine positions; duration of reflux episode; the number of reflux episodes longer than 5 minutes; symptom score; and the mean duration of reflux episodes. $^{6,9,12}$ A reflux episode is defined as a drop in $\mathrm{pH}$ below 4 lasting for $\geq 10$ seconds. $^{13}$

Compared with traditional 24-hour catheter-based $\mathrm{pH}$ moni- toring, the Bravo $\mathrm{pH}$ data can be recorded for 48 hours or more. Esophageal acid exposures for the first day, second day and combined 48 hours are calculated separately. ${ }^{10}$ In patients who underwent endoscopic guidance under sedation, it has been proposed that to eliminate the effects of sedatives on the LES, the first 6 hours of $\mathrm{pH}$ data should be excluded in the analysis of results. ${ }^{10}$

There is day-to-day variability in acid exposure and therefore an extended recording beyond 24 hours may be preferable. ${ }^{10}$ Ang et $\mathrm{al}^{5}$ compared Bravo $\mathrm{pH}$ monitoring with that of conventional $\mathrm{pH}$ catheter but the mean acid exposure time was not significantly different. However, the Bravo capsule seemed to have recorded fewer reflux episodes, a finding similar to a previous study by Varannes et al. ${ }^{9}$ Acid exposure values were found to be $1.2 \%$ greater with the catheter system compared to the Bravo system. ${ }^{5,9}$ Extended monitoring becomes of value in this case and Ang et $\mathrm{al}^{5}$ noted a $61 \%$ positive diagnostic yield with an incremental diagnostic yield of $30 \%$ seen at 48-hour period. Moreover, monitoring can be extended up to 96 hours to increase the chance of detecting reflux events and to establish symptom association. ${ }^{5}$ Therefore, it can be used to evaluate medications responses or to document acid reflux in patients with refractory symptoms despite therapy.

To assess the temporal relationship between acid refluxes and symptoms, the patient's symptom index score (SI), symptom sensitivity index (SSI) and symptom association probability (SAP) are utilized. SI, first described by Wiener et $\mathrm{al}^{19}$ in 1988 , is defined as the number of times reflux symptoms occured when $\mathrm{pH}$ was $<4$ divided by the total number of symptoms reported multiplied by 100. SSI refers to the percentage of symptom-related reflux episodes while the SAP pertains to a statistical parameter calculated to quantify the likelihoods that the patient's symptoms are related to reflux. Significant symptom-reflux association occurs when the SSI
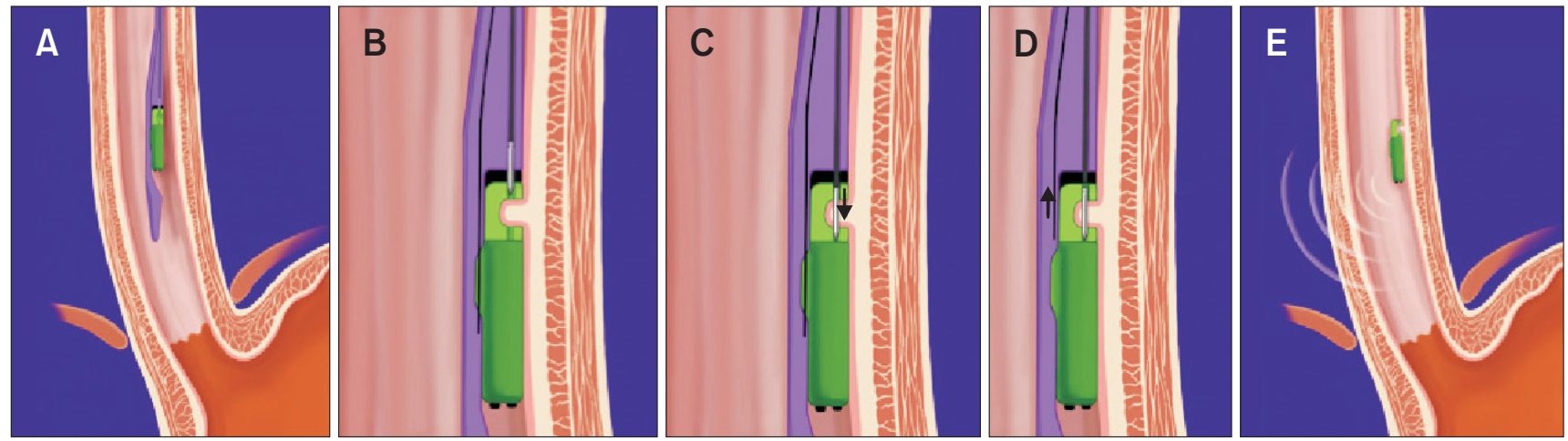

Figure 2. Steps in placement of the Bravo capsule. (A) Position Bravo $\mathrm{pH}$ capsule. (B) Apply suction to catheter until $700 \mathrm{mmHg}$ is reached for 60 seconds. (C) Depress plunger to advance pin. (D) Release capsule by rotating the plunger clockwise. (E) Begin $\mathrm{pH}$ recording. 
is $\geq 10 \%, \mathrm{SI}$ is $\geq 50 \%$, and $\mathrm{SAP}$ is $>95 \%$.,13

\section{Results}

An abnormal composite $\mathrm{pH}$ score is the most accurate method to identify presence of GERD. ${ }^{21}$ However, optimal threshold cut-off values are yet to be standardized. Penagini et al ${ }^{11}$ in 2007, explained that a $\mathrm{pH}$ monitoring study is considered normal when esophageal acid exposure is in the normal range and the SI is less than 0.5 .

A pathological esophageal acid exposure in overall 48-hour duration is characterized by the total percentage of time $\mathrm{pH}<4$ greater than $5.3 \%$ according to Pandolfino et al (Table 1). ${ }^{22}$ Later, Ayazi et $\mathrm{al}^{2}$ described greater than $4.9 \%$ for the total percentage of $\mathrm{pH}<4$ over 48 -hour period but Wenner et $\mathrm{al}^{23}$ defined an abnormal esophageal acid exposure as $>4.4 \%$ after 48 -hour (Table 1 ). ${ }^{23}$ The presence of an abnormal composite $\mathrm{pH}$ score in either the first or second 24-hour had a sensitivity of $93 \%$ but specificity and positive predictive value of $100 \%$ for a diagnosis of GERD. ${ }^{21}$

On the other hand, there is limited data on normal $\mathrm{pH}$ thresholds from Asia compared to the West. In a recent study by Ang et $\mathrm{al}^{7}$ they determined the following data in a cohort of Singaporeans (age range 22-50, with two-thirds males and two-thirds of Chinese ethnicity): total percentage time $\mathrm{pH}<4$ at 24 hours was $7.4 \%$, at 48 hours was $6.3 \%$ and overall 48 hours study was $5.8 \%$ (Table 1 ). ${ }^{7}$ Besides ethnicity, the differences between Ang et $\mathrm{al}^{7}$ and other reported Western studies could be due to unequal gender and age distribution. More studies are needed from Asia to confirm and to compare the findings with those from the West. Based on the above observations, for now in Asia, the recommended normal values for total percentage of time $\mathrm{pH}<4$ would be close to those reported by Ang et al, ${ }^{7}$ that is $<7.4 \%$ at 24 hours, $<6.3 \%$ at 48 hours, and $<5.8 \%$ for overall 48 hours. However, it is our view that the 24-hour $\mathrm{pH}$ value of $<7.4 \%$ was too high, and we recommend a lower level, similar to what was reported by Pandolfino et al, ${ }^{22}$ that is $<5.8 \%$.

\section{Indications}

In 2005, the United States Food and Drug Administration approved the use of Bravo $\mathrm{pH}$ monitoring system for the evaluation of patients with GERD. The American Gastroenterology Association also approved the use of Bravo capsule for documenting adequacy of PPI therapy in Barrett's esophagus and to evaluate atypical symptoms unresponsive to PPI therapy. ${ }^{15}$

Table 2 summarizes the clinical uses of the capsule monitoring system.

Many gastroenterologists in Asia often face the dilemma in choosing the appropriate $\mathrm{pH}$ diagnostic tools. In the ideal situation where cost is not an issue, we would recommend Bravo capsule for its better tolerability, and for its ability to evaluate the efficacy onPPI. If cost is an issue then $\mathrm{pH}$ probe is recommended for exclusion of GERD off-PPI. For non-acidic reflux detection, the $\mathrm{pH}$ impedance probe is clearly superior over both $\mathrm{pH}$ alone and Bravo capsule. Besides, the $\mathrm{pH}$-impedance probe can be performed both off- and on-PPI, and the study duration for $\mathrm{pH}$-impedance can be potentially extended beyond 24 hours. However, besides cost, tolerability is an issue with the $\mathrm{pH}$-impedance probe.

Relative contraindications to the use of Bravo capsule include pregnant patients, history of underlying bleeding diathesis, the presence of esophageal strictures, varices, diverticula and severe esophagitis with intestinal metaplasia. ${ }^{5,12}$ Likewise, patients with previous

Table 2. Indications for Esophageal $\mathrm{pH}$ Testing Using the Bravo Capsule System (Adapted from Lacy et al, ${ }^{3}$ Ang et al, ${ }^{5}$ and Pandolfino and Kwiatek ${ }^{15}$ )

1. Evaluation of patients with GERD and normal EGD

2. Patients considered for endoscopic or surgical reflux therapy

3. Patients with typical GERD symptoms who fail empiric PPI therapy

4. Patients with atypical symptoms who fail empiric PPI therapy

5. Alternative for patients who cannot tolerate catheter-based monitoring

GERD, gastroesophageal reflux disease; EGD, esophagogastroduodenoscopy.

Table 1. Threshold Values of Esophageal Acid Exposure Using Bravo pH Readings

\begin{tabular}{lccccc}
\hline & $\begin{array}{c}\text { Pandolfino et } \mathrm{al}^{22} \\
(2003)\end{array}$ & $\begin{array}{c}\text { Wenner et al } \\
(2005)\end{array}$ & $\begin{array}{c}\text { Ayazi et al }^{23} \\
(2009)\end{array}$ & $\begin{array}{c}\text { Ang et al }^{7} \\
(2013)\end{array}$ & $\begin{array}{c}\text { Recommended } \\
\text { normal Asian values }\end{array}$ \\
\cline { 2 - 5 } & \multicolumn{5}{c}{ Median (95 th percentile) } \\
Total \% time $\mathrm{pH}<4$ at 24 hours & $2.2(5.8)$ & $0.7(3.3)$ & $1.1(6.3)$ & $1.7(7.4)$ & $<5.8$ \\
Total \% time $\mathrm{pH}<4$ at 48 hours & $1.8(6.6)$ & $1.0(0.6)$ & $1.2(5.9)$ & $1.5(6.3)$ & $<6.3$ \\
Overall 48-hour duration & $2.0(5.3)$ & $0.8(4.4)$ & $1.4(4.9)$ & $1.9(5.8)$ & $<5.8$ \\
\hline
\end{tabular}


upper GI surgery, history of Zollinger-Ellison syndrome, active malignancy or Crohn's disease are not recommended for this procedure. ${ }^{5}$ Other contraindications include presence of a pacemaker or defibrillator which may interfere with signal transmission. ${ }^{12,13}$

\section{Other Clinical Utility}

In the pathophysiology of GERD, many patients develop reflux symptoms in the post-prandial state but this is a paradox since meals buffer the stomach acid. ${ }^{16}$ An area of the proximal stomach distal to the squamocolumnar junction (SCJ) eludes the buffering effect of meals, the so-called "acid pocket," and studies have found an association between acid pocket and GERD. In this regard, measuring intragastric $\mathrm{pH}$ in this acid pocket using the Bravo wireless capsule system may be useful. Pandolfino et $\mathrm{al}^{17}$ demonstrated that concurrent measurement of esophageal $\mathrm{pH}(6 \mathrm{~cm}$ proximal to the $\mathrm{SCJ})$ and gastric $\mathrm{pH}(1.5$ to $2 \mathrm{~cm}$ distal to $\mathrm{SCJ})$ using 2 Bravo capsules was feasible and reliable. ${ }^{16}$ Study results showed that the median $\mathrm{pH}$ of the cardia were significantly lower than the median esophageal $\mathrm{pH}$ during reflux events, which is compatible with an acid pocket. ${ }^{17}$ Another study done by Ono et al ${ }^{16}$ showed that the Bravo capsule, attached with multiple hemoclips at the greater curvature of the gastric body, can monitor treatment responses while on histamine receptor blockers.

In the evaluation of patients with non-cardiac chest pain (NCCP), $\mathrm{pH}$ monitoring may also be advantageous especially when they are unresponsive to a therapeutic trial of PPI. Karamanolis et $\mathrm{al}^{24}$ reported that among 32 patients presenting with NCCP, over $60 \%$ had evidence of a pathological esophageal acid reflux and positive symptom index, specifically with the use of 48hour Bravo $\mathrm{pH}$ monitoring. ${ }^{24}$

\section{Trouble-shooting and Potential Complications}

The Bravo capsule is usually well-tolerated and a successful capsule deployment is seen in $98 \%$ to $100 \%$ of cases. ${ }^{12,15}$ After capsule placement, some subjects may experience throat discomfort, bleeding, odynophagia, dysphagia or mild foreign body sensation with eating, and chest discomfort. ${ }^{4,8,12}$ Throat discomfort is seen less in the Bravo system compared to a catheter-based system but esophageal discomfort was reportedly more common with the capsule. ${ }^{15}$ In the presence of severe odynophagia and chest pain $(<2 \%$ of cases) after capsule placement, a chest x-ray is essential to rule out perforation. ${ }^{8,15}$

Technical failures may occur in up to $15 \%$ of cases. ${ }^{21}$ These include poor data transmission (4.5\%), attachment failure (3.4\%), early capsule dislodgement (4.5\%), and detachment failure (1.5\% to
$6.8 \%){ }^{12,21}$ The need for capsule removal was seen in $6 \%$ of cases, and it may be indicated in patients with intolerable and persistent chest discomfort. ${ }^{21}$

Complications, such as GI bleeding and perforations, although rare, have been reported. ${ }^{6}$ A capsule is considered to be detached from the esophagus when the $\mathrm{pH}$ suddenly drops below 2 followed by a sudden increase in $\mathrm{pH}>6$ which corresponds to capsule passage through the bowel. ${ }^{9,11}$ The capsule usually detaches within 5 days. In cases where capsule failed to detach within 5 days as confirmed from radiological identification, endoscopic retrieval may be warranted. ${ }^{21}$ Removal is performed by applying gentle pressures to the capsule using the tip of an endoscope to dislodge the capsule followed by its retrieval. ${ }^{13}$

\section{Limitations}

The cost is an important consideration especially in the Asian developing countries. A complete Bravo system costs around \$25 704 . A single-use Bravo capsule with delivery device costs $\$ 225$ compared to the conventional trans-nasal $\mathrm{pH}$ catheter which costs $\$ 62 .^{12} \mathrm{In}$ addition, standardized thresholds for abnormal esophageal acid reflux in Asia are lacking and the optimal recording periods is still in question. Furthermore, a higher rate of technical failures among inexperienced operators and associated chest pain symptom needing removal are other limitations to consider.

\section{Conclusion}

The Bravo $\mathrm{pH}$ monitoring system is a safe and well-tolerated alternative to the catheter-based $\mathrm{pH}$ monitoring. It is patientfriendly with the ability for prolonged $\mathrm{pH}$ recording. The Bravo capsule is recommended in the evaluation of patients with refractory GERD, prior to antireflux surgery, and monitoring of patient responses during therapy. Optimal threshold values have yet to be standardized particularly in Asia and prospective studies are still required to formulate appropriate interpretation guidelines.

Acknowlegements: Reckitt-Benckiser has provided funding for research in relation to this article.

Financial support: This study was supported by Reckitt-Benckiser.

Conflicts of interest: None.

Author contributions: Yeong Yeh Lee and Rona Marie A Lawenko provided the idea, performed studies, and written the 
manuscript.

\section{References}

1. Jung, HK. Epidemiology of gastroesophageal reflux disease in Asia: a systematic review. J Neurogastroenterol Motil 2011;17:14-27.

2. Ayazi S, Lipham J, Portale G, et al. Bravo catheter-free $\mathrm{pH}$ monitoring: normal values, concordance, optimal diagnostic thresholds, and accuracy. Clin Gastroenterol Hepatol 2009; 7:60-67.

3. Lacy BE, Weiser K, Chertoff J, et al. The diagnosis of gastroesophageal reflux disease. Am J Med 2010;123:583-592.

4. Kwiatek MA, Pandolfino JE. The Bravo $\mathrm{pH}$ capsule system. Dig Liver Dis 2008;40:156-160.

5. Ang D, Teo EK, Ang TL, et al. To Bravo or not? A comparison of wireless esophageal $\mathrm{pH}$ monitoring and conventional $\mathrm{pH}$ catheter to evaluate non-erosive gastroesophageal reflux disease in a multiracial Asian cohort. J Dig Dis 2010;11:19-27.

6. Taghavi SA, Ghasedi M, Saberi-Firoozi M, et al. Symptom association probability and symptom sensitivity index: preferable but still suboptimal predictors of response to high dose omeprazole. Gut 2005;54:1067-1071.

7. Ang $\mathrm{D}, \mathrm{Xu} \mathrm{Y}$, Ang TL, et al. Wireless esophageal pH monitoring: establishing values in a multiracial cohort of asymptomatic Asian subjects. Dig Liver Dis 2013;45:371-376.

8. Wood RK. Endoscopic aspects in diagnosis of gastroesophageal reflux disease and motility disorders: Bravo, capsule, and functional lumen imaging probe. Tech in Gastrointest Endosc 2014;16:2-9.

9. des Varannes SB, Mion F, Ducrotté P, et al. Simultaneous recordings of esophageal acid exposure with conventional $\mathrm{pH}$ monitoring and a wireless system (Bravo). Gut 2005;54:1682-1686.

10. Ayazi S, Hagen JA, Zehetnes J, et al. Day-to-day discrepancy in Bravo $\mathrm{pH}$ monitoring is related to the degree of deterioration of the lower esophageal sphincter and severity of reflux disease. Surg Endosc 2011;25:2219-2223.

11. Grigolon A, Bravi I, Cantù P, Conte D, Penagini R. Wireless pH monitoring: better tolerability and lower impact on daily habits. Dig Liver Dis 2007;39:720-724.

12. Chotiprashidi P, Liu J, Carpente S, et al. ASGE Technology Status
Evaluation Report: wireless esophageal $\mathrm{pH}$ monitoring system. Gastrointest Endosc 2005;62:485-487.

13. Bredenoord AJ, Weunsten NL, Smout AJ. Symptom association analysis in ambulatory gastroesophageal reflux monitoring. Gut 2005;54:18101817.

14. Pandolfino JE, Schreiner MA, Lee TJ, Zhang Q, Boniquit C, Kahrilas PJ. Comparison of the Bravo wireless and digitrapper catheter-based $\mathrm{pH}$ monitoring systems for measuring esophageal acid exposure. Am J Gastroenterol 2005;100:1466-1476.

15. Pandolfino JE, Kwiatek MA. Use and utility of the Bravo $\mathrm{pH}$ capsule. J Clin Gastroenterol 2008;42:571-578.

16. Ono S, Kato M, Ono P, Asaka M. New method for long-term monitoring of intragastric $\mathrm{pH}$. World J Gastroenterol 2007;13:6410-6413.

17. Pandolfino JE, Schreiner MA, Zhang Q, Kahrilas PJ. Bravo capsule placement in the gastric cardia: a novel method for analysis of proximal stomach acid environment. Am J Gastroenterol 2005;100:1721-1727.

18. Sofi AA, Filipiak C, Sodeman T, Ahmad U, Nawras A, Daboul I. Comparison of esophageal placement of Bravo capsule system under direct endoscopic guidance with conventional placement method. Clin and Exp Gastroenterol 2010;3:147-151.

19. Wiener GJ, Richter JE, Copper JB, Wu WC, Castell DO. The symptom index: a clinically omportant parameter of ambulatory 24-hour esophageal pH monitoring. Am J Gastroenterol 1988;83:358-361.

20. Nusrat S, Roy PM, Bielefeldt K. Wireless ambulatory $\mathrm{pH}$ studies: manometric or endoscopic guidance? Dis Esophagus 2012;25:26-32.

21. de Hoyos A, Esparza EA. Technical problems produced by the Bravo $\mathrm{pH}$ test in nonerosive reflux disease patients. World J Gastroenterol 2010;16:3183-3186.

22. Pandolfino JE, Richter JE, Guardino JM, et al. Ambulatory esophageal pH monitoring using a wireless system. Am J Gastroenterol 2003;98: 740-749.

23. Wenner J, Johnsson F, Johansson J, Oberg S. Wireless oesophageal pH monitoring: feasibility, safety, and normal values in healthy subjects. Scand J Gastroenterol 2005;40:768-774.

24. Karamanolis G, Triantafyllou K, Psatha P, et al. Bravo 48-hour wireless $\mathrm{pH}$ monitoring in patients with non-cardiac chest pain. Objective gastroesophageal reflux disease parameters predict the responses to proton pump inhibitors. Neurogastroenterol Motil 2012;18:169-173. 